\title{
Body size and spatial variation of community structure in subarctic intertidal boulder fields
}

\author{
Christopher W. McKindsey*, Edwin Bourget \\ GIROQ, Dèpartement de Biologie, Universitè Laval, Quèbec, Quèbec G1K 7P4, Canada
}

\begin{abstract}
The influence of body size of organisms examined on the spatial variation in the structure of mussel communities (evaluated as Shannon-Wiener diversity, taxonomic richness, and density) in boulder fields was evaluated for 4 spatial scales $(<1 \mathrm{~m}, 10 \mathrm{~m}, 10 \mathrm{~km}$, and $50 \mathrm{~km})$. A number of factors (orientation of mussel communities on boulders, water flux and intertidal height) that potentially influence community structure at the smallest scale examined were also investigated. Overall, although body size usually influenced the significance of the different spatial scales examined in parametric analyses, the proportion of the total variance explained by each spatial scale was relatively constant for each size class and index of community structure calculated. Community structure was typically most variable at the smallest spatial scale examined, with progressively larger spatial scales explaining less and less of the total variation among samples. The multivariate ANOSIM tests, which did not examine variation at the smallest spatial scale, always found significant differences among communities at the $10 \mathrm{~m}$ and $50 \mathrm{~km}$ scales but, depending on the body size examined, did not always detect significant differences among communities at the $10 \mathrm{~km}$ scale. The mean Bray-Curtis similarity among samples decreased with decreasing body size and with increasing spatial scale. As the absolute difference in mean similarities among the different spatial scales examined decreased with increasing body size, we suggest that the ability to distinguish groups using ANOSIM should be greatest for the smallest macro-organisms studied. Variation at the smallest scale was not due to the compass orientation of the communities on boulders. Small-scale variation in water flux and intertidal height had a variable influence on the indices of community structure, and they were also a function of body size. Potential mechanisms responsible for the observed spatial variation are discussed.
\end{abstract}

KEY WORDS: Spatial variation - Body size $\cdot$ Rocky shore $\cdot$ Intertidal communities - Diversity · Richness $\cdot$ Density $\cdot$ Community structure

\section{INTRODUCTION}

Ecological communities typically vary across different spatial scales and such variation has important implications for most ecological and evolutionary processes (Kolasa \& Pickett 1991, Ricklefs \& Schluter 1993). To better understand the processes determining such variation, studies in the marine environment have

*Present address: Centre for Research on Ecological Impacts of Coastal Cities, Marine Ecology Laboratories, A11, University of Sydney, New South Wales 2006, Australia.

E-mail: cmckinds@bio.usyd.edu.au increasingly employed hierarchical sampling designs to determine the spatial scales at which communities vary (e.g., Caffey 1985, Morrisey et al. 1992, Lindegarth et al. 1995, Archambault \& Bourget 1996, Li et al. 1996, Schoch \& Dethier 1996, Underwood \& Chapman 1996, David et al. 1997, Legendre et al. 1997, Blanchard \& Bourget 1999, Menconi et al. 1999).

All else being equal, physical factors account for more of the variation in community structure at larger spatial scales, whereas the converse is true of biological factors (Barry \& Dayton 1991, Cornell \& Lawton 1992). In benthic marine systems variation in hydrodynamic processes may affect community structure at 
scales varying from $>100 \mathrm{~km}$ (Bustamante et al. 1995, Connolly \& Roughgarden 1998) to kilometres (Archambault \& Bourget 1999) to metres (Breitburg et al. 1995, Cusson \& Bourget 1997) to millimetres or smaller (Jumars \& Nowell 1984, Bourget et al. 1994). Unfortunately, as scale decreases so too does our understanding of the increasing hydrodynamic complexity associated with it (Downes \& Keough 1998). Hydrodynamic processes resulting from substratum heterogeneity at local (tens of meters) and patch $(<\mathrm{m})$ scales influence a wide range of biological effects and must be controlled for whenever examining smaller-scale effects (Eckman 1983, 1996). They have been shown to influence competition (Ólafsson et al. 1994, Breitburg et al. 1995), feeding/predation rates (Palmer 1986, Abelson et al. 1993), and sediment dynamics (Jumars \& Nowell 1984, Muschenheim 1987).

To date, most of the work done on the effect of hydrodynamics at small scales has been done either for soft-sediment systems or with recruitment panels or branching structures. Flow patterns around boulders and other bluff objects are at least as complex as those produced by the perfect cylinders, panels, etc., that are used in most laboratory studies (Jumars \& Nowell 1984, Downes \& Keough 1998). Among other factors, concentration of passive particles at different locations around bluff objects depends on the roughness and size of the object itself, flow velocity and the size and density of the particles (Patterson 1984, Abelson et al. 1993).

Few studies have considered the influence of substratum heterogeneity in the form of high-relief structures, such as boulders, on recruitment or community structure, and none have considered the communities that develop on the boulders themselves. In this study we examine how the structure of mussel communities from boulder fields characteristic of northern and subarctic shores in the St. Lawrence estuary, Canada, vary between shores $\sim 50 \mathrm{~km}$ apart, between sites $\sim 10 \mathrm{~km}$ apart, between boulders $\sim 10 \mathrm{~m}$ apart and within boulders $(<1 \mathrm{~m}$ between samples).

Variation in the abundance of numerous species of intertidal organisms has been shown to be great at small $(1 \mathrm{~m})$ spatial scales (Underwood \& Chapman 1996, Menconi et al. 1999). To better understand the factors that may be responsible for similar effects in the boulder fields examined in this study, we sought correlations between different factors and the structure of communities examined. In the intertidal zone, 2 of the dominant forces that structure communities are exposure and thermal/desiccation stress (Underwood \& Denley 1984). We predicted a priori that thermal/desiccation stress should be greatest on southerly sides of boulders, whereas wave exposure should be greatest on seaward sides. Mussel communities were thus sampled from each of the north, east, south and west sides of boulders. Sampling on the 2 shores of the St. Lawrence (North and South) keeps 1 factor, thermal/ desiccation stress, constant while varying exposure (waves on the north and south shores come predominantly form the south and north, respectively). Interactions between shores and orientations would suggest wave exposure is more important in structuring communities, whereas a simple orientation effect would suggest thermal/desiccation stress to be more important.

As the size of intertidal organisms may be inversely related to their susceptibility to desiccation (Brawley \& Johnson 1993) and thermal stress (Helmuth 1998), it was further predicted that thermal/desiccation effects, if they exist, should be greatest for the smallest organisms. We thus examined whether spatial patterns are consistent for different size classes of organisms. It was predicted that the size of the organisms examined would interact with sampling orientation and shore such that any effect of the latter 2 factors would be greater for smaller organisms.

Although many authors have stressed the importance of considering a range of body size classes when studying community structure (Peters 1983, Bell \& Woodin 1984, Thompson et al. 1996, Hurlbert 1997), few have done so. To date, the only study that considers how body size influences community structure at a range of spatial scales is that of James et al. (1995). However, the system studied (Australian semitropical subtidal soft-sediment macrofauna) differed greatly from the one studied here (subarctic intertidal hardbottom macrofauna), and the smaller size classes they used also included organisms from larger size classes, making conclusions about different size-class assemblages impossible to obtain. As with paradigms about varying taxonomic precision and spatial patterns of macrofauna (Chapman 1998), the influence of body size should also be tested at various locations before the effects may be accepted as having some generality.

The system studied is rather species-poor and comparing the spatial variation in the abundance of different size classes of each taxon present would not be very fruitful, as only 1 taxon, the mussel Mytilus spp. (Mytilus edulis and M. trossulus, hereafter Mytilus), is commonly found in more than a couple of size classes. We thus concentrated on more comprehensive indices of community structure (Shannon-Wiener diversity, richness, density) and nonparametric multivariate analyses of community structure.

\section{METHODS}

Study area. The study was done in the St. Lawrence estuary, Canada (Fig. 1). Typical summer salinity (30 


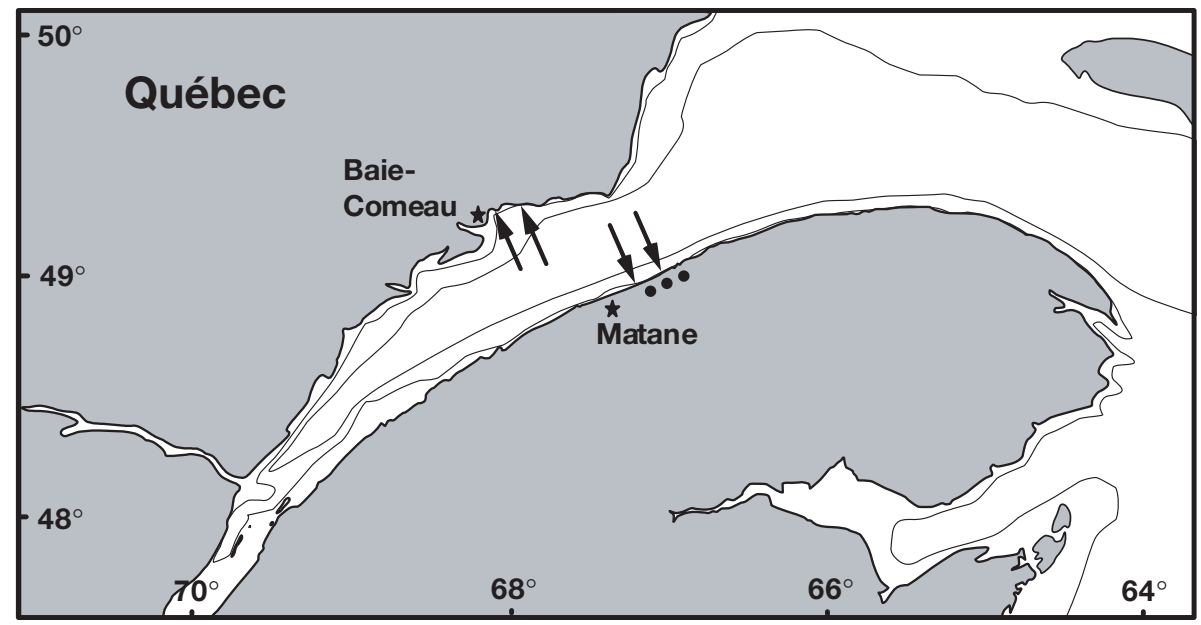

Fig. 1. Location of the 3 sites sampled in 1995 (indicated by circles: Site A, extreme west; B, middle; and C, extreme east) and 1996 (indicated by arrows: Sites N1, N2, S1, and S2, for the northwest, northeast, southwest and southeast sites, respectively) sampling seasons

and $27 \mathrm{ppt})$ and temperature $\left(10\right.$ and $\left.14^{\circ} \mathrm{C}\right)$ measurements for the general areas around the sites studied on the north and south shores, respectively, may be found in Fradette \& Bourget (1980). Tides along both shores are diurnal, with mean and maximal fluctuations of approximately 2.6 and $4.1 \mathrm{~m}$, respectively. All the sites studied were boulder fields (boulders typically 0.3 to $1 \mathrm{~m}$ in diameter overlaying an unconsolidated substrate of sand and gravel) along straight coastlines. Because of an intense annual scouring by ice in the area, mussel communities are mostly limited to irregularities in the substrate (Bergeron \& Bourget 1986) and exist as well-defined collars around the middle of boulders in the sites studied.

Sampling. Mussel communities were sampled from boulders measuring 0.35 to $0.8 \mathrm{~m}$ in diameter that were randomly chosen within 5 to $10 \mathrm{~m}$ of each other within each site. For the spatial scale experiments (1995 and 1996), a $10 \times 10 \mathrm{~cm}$ sample was taken from the upper limit of the mussel collar from each of the north, east, south and west orientations on each boulder. Sampling at all sites for each year for the hierarchical studies was done at the same intertidal level (lower middle) as determined by the zonation of the different species. Depending on the year, samples were either frozen (1995) or fixed in formalin and stored in $70 \%$ alcohol (1996) until laboratory analysis. In the lab, samples were passed through a series of 5 screens $(0.5,1,2,4$ and $8 \mathrm{~mm}$ ). The animals on each screen were identified to the lowest taxonomic level possible, counted, blotted dry and weighed.

In 1995, communities from 6 boulders were sampled from each of 3 sites chosen at random and separated by about $10 \mathrm{~km}$ on the south shore of the St. Lawrence estuary (Fig. 1). Unfortunately, freezing the samples gave less than ideal results (many of the smaller worms were fragmented and not identifiable) and thus calculated variances were suspect. In 1996, 8 boulders were sampled within each of 2 sites chosen at random and separated by about $10 \mathrm{~km}$ on both the north and south shores. Sites on the north and south shores were separated by about $50 \mathrm{~km}$ (Fig. 1). Thus both the 1995 and 1996 data sets considered spatial scales ranging from $<1 \mathrm{~m}$ (within boulders, Orientation) to $\sim 10 \mathrm{~m}$ (among boulders within sites, Boulder) to $\sim 10 \mathrm{~km}$ (between or among sites, Site). The 1996 data set also examined spatial variation at the $50 \mathrm{~km}$ (between shores, Shore) scale.

A further experiment was done at 1 site on the south shore in 1996 to examine whether water flux varies among orientations around boulders and if the structure of the communities is related to this variation. Because of logistical constraints, this study did not use a randomized block design. Rather, 6 further randomly selected boulders were identified for sampling for each of the 4 orientations of interest and the location of these future 'quadrats' marked on the boulders by scratching the boulders directly above the mussel collar. Plastic anchors were placed in holes drilled into the boulders $5 \mathrm{~cm}$ below the upper limit of the mussel collar and $5 \mathrm{~cm}$ on either side of each quadrat (i.e., 2 positions per quadrat). On 6 separate dates in June to September, pre-weighed plaster buttons $(\sim 1 \mathrm{~cm}$ high) fixed to screws were placed with their bottoms flush with the mussel beds at each position by screwing them into the plastic anchors. These were removed following 1 tidal cycle $(12 \mathrm{~h})$ and the plaster loss determined as an index of water flux 
(Muus 1968). The intertidal height of each position was determined by surveyor's transect and stadia and also evaluated as a potentially important factor influencing community structure. Following the erosion experiments, the predetermined quadrats were sampled and treated as outlined above.

Statistical analysis. Four indices of community structure were calculated: Shannon-Wiener diversity calculated from the density and biomass of each taxa, species richness, and density. In all cases, the results for diversity calculated from the biomass were equivalent to those calculated from density and, for brevity, we present only the results from the latter, hereafter diversity. Each was analyzed separately by a randomized blocks (boulders) ANOVA design for repeated measures with body size (Size) considered as the repeated factor. Shore, Site and Boulder were considered random factors and Orientation a fixed factor. In all cases, the assumption of sphericity (tested by Mauchly's criterion) was not met, and the probabilities presented are those corrected by a Huynh-Feldt adjustment (Tabachnick \& Fidell 1989). The proportion of the total variation in community structure (richness, diversity and density) associated with the 4 spatial scales examined was estimated by calculating variance components (Underwood 1997) for the 5 size classes of organisms examined in 1996. Variation in water flux was evaluated using a repeated-measures ANCOVA using the means from the 2 positions for each quadrat from each sampling date as data. The influence of intertidal height (High) and the mean (of the 6 sample dates) and maximal (the sampling date with the highest plaster loss) water flux on the various indices of community structure were evaluated by step-wise regression. Only the density data needed to be transformed $[\ln (x+1)]$ to meet the assumptions of homoscedasticity and normality, as confirmed by the examination of residual plots (Tabachnick \& Fidell 1989).

Multivariate community structure was compared using ANOSIM (Clarke 1993) using matrices of BrayCurtis similarities calculated from fourth-root transformed density data for each of the 5 size classes. These similarity matrices were also used to construct non-metric multidimensional scaling (nMDS) plots to visually evaluate variation in community structure.

For any given model, modification of the critical $\alpha$ employed (0.05) for post-hoc testing between means (LSMeans tests, SAS Institute 1996) and nonparametric community structure (pair-wise contrasts) was done using sequential Bonferroni adjustments (Rice 1989). All parametric statistics were performed using the SAS system for Windows (SAS Institute 1996). Nonparametric statistical tests were performed using PRIMER (Carr 1996). nMDS ordinations were calculated by either SAS or PRIMER.

\section{RESULTS}

Overall, the mussel communities examined were depauperate as compared to other mussel communities studied in other locations (in all samples taken, a total of 26 taxa were observed). In terms of abundance, the dominant species observed were, in order, Mytilus, Littorina saxatilis, Littorina obtusata, oligochaetes, and the isopod Jaera marina (data not shown).

\section{5 data set}

As noted above, the preservation method used (i.e., freezing) in this part of the study resulted in some of the specimens collected, particularly the smaller ones, being either unidentifiable or lost in lab processing. Because of this and because the largest spatial scale was not examined in 1995, we present only the results from the repeated-measures design and the ANOSIM tests.

Both diversity and density varied among sites (10 km scale) and richness and diversity varied among boulders within sites (10 m scale, Table 1). However, these factors also interacted in various ways with Size, such that its effect varied among boulders within sites and usually ( 3 of 4 cases) also among sites (Table 1). The source of the significant Size $\times$ Site interaction for both diversity and richness is clear from Fig. 2 as the diversity of the smallest organisms at Site C is significantly lower than that of the other 2 sites. The significant Size $\times$ Site interaction for density indicates that the 3 sites differed significantly in the density of organisms $>8 \mathrm{~mm}$ but not for other size classes (Fig. 2).

The size of the organisms examined also influenced the outcome of the multivariate nonparametric ANOSIM tests. Community structure varied among boulders for all size classes but only among sites for the 0.5 and $8 \mathrm{~mm}$ size classes (Table 2). All sites differed significantly for the $0.5 \mathrm{~mm}$ fraction, but only Sites B and $\mathrm{C}$ differed significantly for the $8 \mathrm{~mm}$ fraction. nMDS ordination highlights these trends (Fig. 3). Despite the great overlap of the symbols for the $0.5 \mathrm{~mm}$ size class, Sites A, B, and C cluster largely in different areas of the Figure. Likewise for the $8 \mathrm{~mm}$ size class, Sites B and C cluster mostly in the upper and lower half of the plot, respectively, whereas Site A is more uniform over the entire plot. Note that for the $8 \mathrm{~mm}$ size class most data points cluster in a perpendicular line in the left of the plot. This represents the predominance of mussels in this size class, and those data points not within this grouping represent the samples that contain variable numbers of the other, more rare, large species. 
Table 1. Results of repeated-measures nested ANOVA examining the influence of 3 scales of spatial variation (Site, $10 \mathrm{~km}$ scale; Boulder, $10 \mathrm{~m}$ scale; Orientation, $<1 \mathrm{~m}$ scale) on the diversity, richness, and density $\left(100 \mathrm{~cm}^{-2}\right)$ of benthic intertidal mussel communities for 5 size classes of organisms (Size, repeated factor) for the 1995 data set. The density data were log $(x+1)$-transformed to meet the assumptions of the statistical tests. Because of non-sphericity, probabilities given are those calculated using an Huynh-Feldt adjustment. Statistically significant values are indicated in bold

\begin{tabular}{|c|c|c|c|c|c|c|c|c|c|c|}
\hline \multirow[t]{2}{*}{ Source of variation } & \multirow[t]{2}{*}{$\mathrm{df}$} & \multicolumn{3}{|c|}{ Diversity } & \multicolumn{3}{|c|}{ Richness } & \multicolumn{3}{|c|}{ Density } \\
\hline & & MS & $F$ & $\mathrm{p}$ & MS & $F$ & $\mathrm{p}$ & MS & $F$ & $\mathrm{p}$ \\
\hline Site & 2 & 0.6679 & 3.83 & 0.0453 & 16.5778 & 1.62 & 0.2311 & 4.7232 & 6.16 & 0.0111 \\
\hline Boulder(Site) & 15 & 0.1743 & 3.69 & 0.0003 & 10.2483 & 3.10 & 0.0017 & 0.7667 & 0.88 & 0.5896 \\
\hline Orientation & 3 & 0.1129 & 3.37 & 0.0959 & 4.6027 & 1.31 & 0.3558 & 0.7021 & 0.53 & 0.6797 \\
\hline Orientation $\times$ Site & 6 & 0.0335 & 0.71 & 0.6441 & 3.5222 & 1.06 & 0.3978 & 1.3306 & 1.53 & 0.1912 \\
\hline Error & 45 & 0.0473 & & & 3.3091 & & & 0.8714 & & \\
\hline Size & 4 & 19.3737 & 400.85 & 0.0001 & 409.4264 & 279.90 & 0.0001 & 143.5551 & 642.60 & 0.0001 \\
\hline Size $\times$ Site & 8 & 0.3887 & 4.35 & 0.0003 & 10.1160 & 3.76 & 0.0013 & 3.3796 & 4.72 & 0.0002 \\
\hline Size $\times$ Boulder(Site) & 60 & 0.0893 & 1.85 & 0.0011 & 2.6928 & 1.84 & 0.0011 & 0.7156 & 3.20 & 0.0001 \\
\hline Size $\times$ Orientation & 12 & 0.0270 & 1.02 & 0.4599 & 0.4708 & 0.78 & 0.6634 & 0.0908 & 0.65 & 0.7783 \\
\hline Size $\times$ Orientation $\times$ Site & 24 & 0.0264 & 0.55 & 0.9586 & 0.6021 & 0.41 & 0.9937 & 0.1394 & 0.62 & 0.8926 \\
\hline Error & 180 & 0.0483 & & & 1.4627 & & & 0.2233 & & \\
\hline
\end{tabular}

A

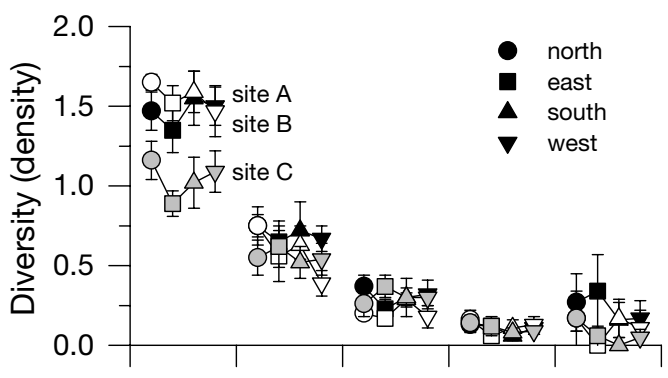

B

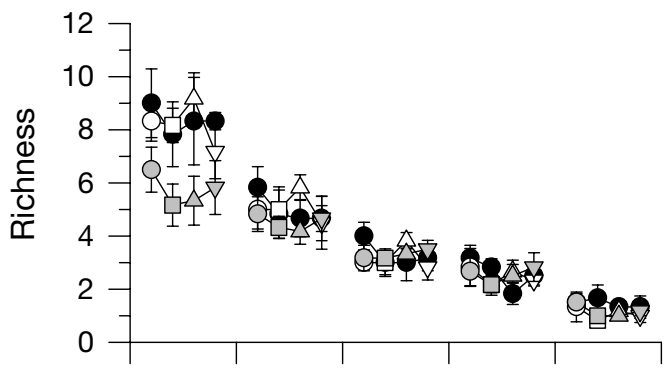

C

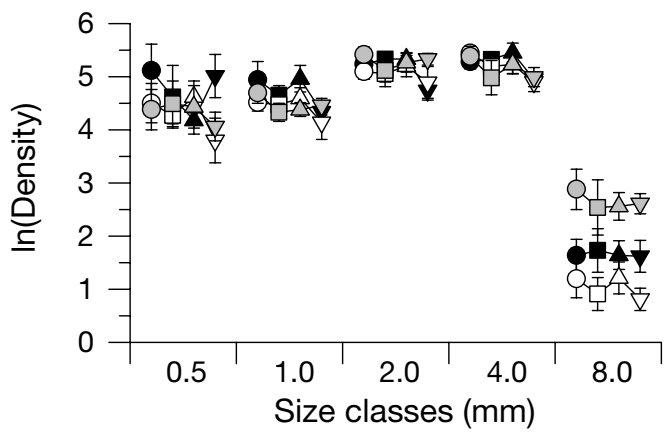

Fig. 2. Mean $( \pm \mathrm{SE})$ Shannon-Wiener diversity (A), richness (B), and density $100 \mathrm{~cm}^{-2}$ (C) of organisms within mussel communities at 4 compass ordinations on boulders from 3 locations as a function of organism size in 1995

\section{6 data set}

An initial running of the full model for all indices measured showed that the factor Orientation $\times$ Site (Shore) was never significant ( $p>0.25$ in all cases both by itself and when interacting with Size) and was thus removed to increase the power of the statistical test (Underwood 1997). As with the 1995 data set, richness, diversity, and density varied significantly among boulders and the effect of size varied with Size (Table 3). Size was also always significant and interacted in variable ways with the other factors. For diversity, variation at both the $10 \mathrm{~m}$ and $10 \mathrm{~km}$ scale was influenced by Size. Orientation $\times$ Shore also interacted with Size but the source of this interaction was not apparent with the decreased power of the post-hoc test. However, if an ANOVA finds a significant effect, at least the 2 most extreme cases must be significantly different (Underwood 1997). This was the contrast between the 0.5 and $4 \mathrm{~mm}$ size classes for Orientation $\times$ Shore $(\mathrm{p}=0.0165)$, which shows roughly the opposite trends. Diversity in the east orientation was least and greatest for $0.5 \mathrm{~mm}$ organisms and greatest and least for the $4 \mathrm{~mm}$ organisms on south and north shores, respectively (Fig. 4). Richness was influenced comparatively little by Size, and only Boulder was significantly influenced by it. Although organisms were typically more abundant on the south than on the north shore, these trends were also influenced by the size of organisms examined (Table 3). In fact, except for the contrasts between the $0.5 \mathrm{~mm}$ size class with both the 2 and $8 \mathrm{~mm}$ size classes, and between the 1 and $4 \mathrm{~mm}$ size classes, all other contrasts were significant.

Comparing the variance components calculated for the 5 size classes examined provides further insight 
into how the different size classes of animals respond to variation at different spatial scales. Overall, variation at the smallest scale $(<1 \mathrm{~m}$, the sum of the variance components associated with the residual error and the
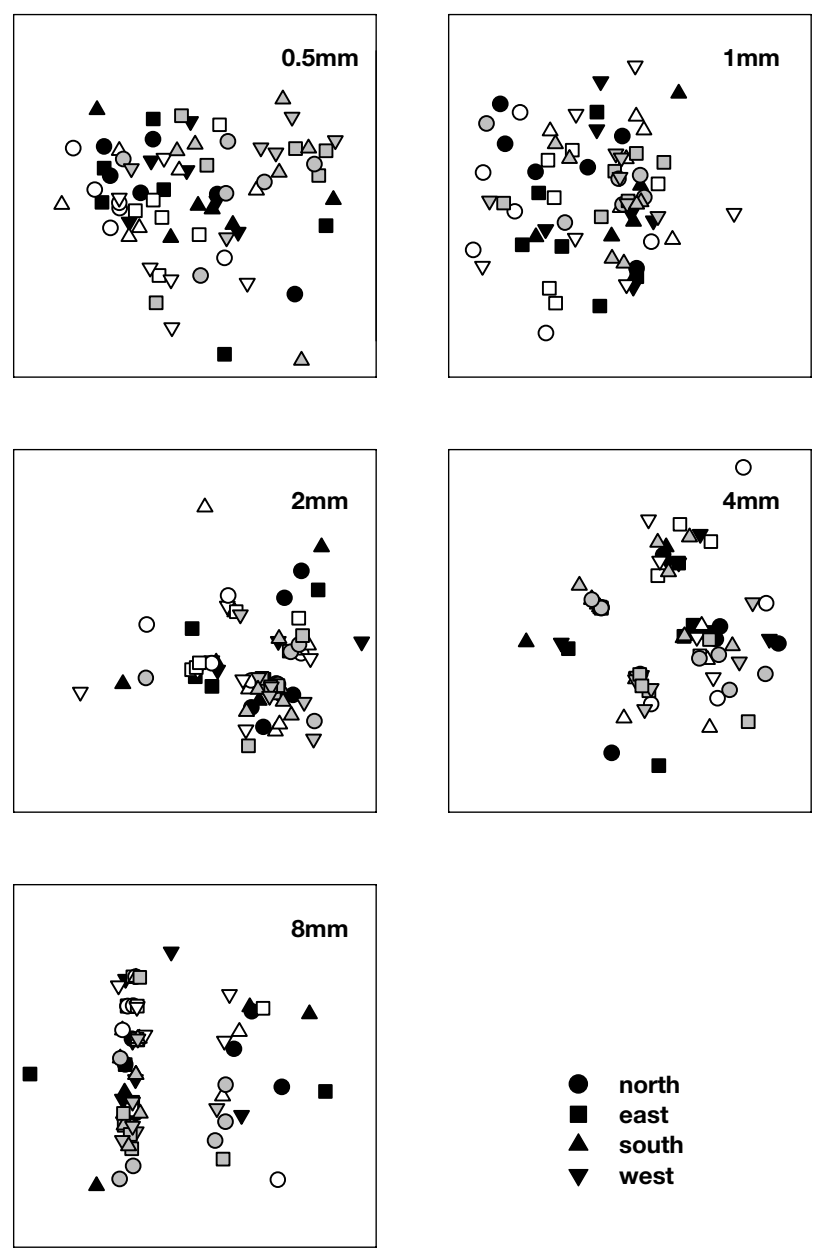

Fig. 3. nMDS plots representing the community structure of 5 size classes of organisms from mussel communities at 4 compass ordinations on boulders from 3 locations in 1995. In all cases, stress values are $=0.17$. White symbols: Site A; black symbols: Site B; grey symbols: Site C factors involving Orientation, summarized as 'Position' in Figs. $5 \& 7$ ) typically explained $>50 \%$ of the total variation among the samples. The only exception was that the density of 2 and $8 \mathrm{~mm}$ animals was greatest at the largest spatial scale. The proportion of the total variance explained by the other spatial scales differs greatly among the different size classes. For example, almost a third of the total variation in Diversity was explained by differences between shores (50 km scale) for organisms in the $1 \mathrm{~mm}$ size class, whereas this factor explained $\leq 8 \%$ of the total variation for each of the other size classes. A similar divergence in the total percentage variance explained by Shore was also seen for the other variables, but the relative ranking and magnitude of the differences for the different size classes varied greatly among the different variables measured. Variation at the $10 \mathrm{~km}$ scale was typically less than that at larger and smaller scales and the magnitude of the differences among size classes less. A considerable proportion of the total variation was also explained by differences among boulders (10 m scale), particularly for the density data, for which this scale accounted for 18 to $31 \%$ of the total variance. Contrary to our predictions, variation due to Orientation explained very little of the total variation among samples. In fact, Orientation or interactions involving this factor typically accounted for $<10 \%$ of the total variation associated with each variable, indicating that it had negligible effects.

Based on the results of the univariate ANOVAs, from the variance components calculated, and from closer visual examination of more detailed nMDS plots (not shown), we are confident that, despite the considerable within-boulder variation in community structure, Orientation had little if any effect on community structure. We thus dropped this factor and used a nested (boulders within sites) ANOSIM to examine differences is the structure of communities among the 4 sites examined. Communities consistently differed among shores and among boulders within sites for all size classes (Fig. 6, Table 4) but not always between sites

Table 2. Results (R statistics) from nested ANOSIMs (Boulders within 3 Sites) and pair-wise contrasts of community structure for the 1995 data set. Separate analyses were performed for each size class. In all cases, probabilities are based on 5000 permutations for the main and nested effects and on 462 permutations for the contrasts. A, B, and C: the 3 sites studied in 1995. ns: $\mathrm{p}>0.05 ;{ }^{*} \mathrm{p}<0.05 ;{ }^{* *} \mathrm{p}<0.01 ;{ }^{* * * *} \mathrm{p}<0.0001$

\begin{tabular}{|c|c|c|c|c|c|}
\hline \multirow{2}{*}{ Source of heterogeneity } & \multicolumn{5}{|c|}{ Size class $(\mathrm{mm})$} \\
\hline & 0.5 & 1.0 & 2.0 & 4.0 & 8.0 \\
\hline Sites & $0.386^{* *}$ & $0.058^{\mathrm{ns}}$ & $0.044^{\mathrm{ns}}$ & $-0.048^{\mathrm{ns}}$ & $0.300^{* *}$ \\
\hline Boulders(Sites) & $0.236^{* * * *}$ & $0.231^{* * * *}$ & $0.219^{* * * *}$ & $0.219^{* * * *}$ & $0.144^{* *}$ \\
\hline A, B & $0.224^{*}$ & $0.163^{\mathrm{ns}}$ & $-0.107^{\mathrm{ns}}$ & $-0.133^{\mathrm{ns}}$ & $0.063^{\mathrm{ns}}$ \\
\hline A, C & $0.410^{*}$ & $0.099^{\mathrm{ns}}$ & $0.091^{\mathrm{ns}}$ & $0.031^{\mathrm{ns}}$ & $0.183^{*}$ \\
\hline $\mathrm{B}, \mathrm{C}$ & $0.531^{*}$ & $-0.044^{\mathrm{ns}}$ & $0.124^{\mathrm{ns}}$ & $-0.048^{\mathrm{ns}}$ & $0.667^{* *}$ \\
\hline
\end{tabular}


Table 3. Results of repeated-measures nested ANOVA examining the influence of 4 scales of spatial variation (Shore, $50 \mathrm{~km}$ scale; Site, $10 \mathrm{~km}$ scale; Boulder, $10 \mathrm{~m}$ scale; Orientation, $<1 \mathrm{~m} \mathrm{scale})$ on the diversity, richness, and density $\left(100 \mathrm{~cm}^{-2}\right)$ of benthic intertidal mussel communities for 5 size classes of organisms (Size, repeated factor) for the 1996 data set. The density data were $\log (x+1)$-transformed to meet the assumptions of the statistical tests. Because of non-sphericity, probabilities given are those calculated using an Huynh-Feldt adjustment. Statistically significant values are indicated in bold

\begin{tabular}{|c|c|c|c|c|c|c|c|c|c|c|}
\hline \multirow[t]{2}{*}{ Source of variation } & \multirow[t]{2}{*}{$\mathrm{df}$} & \multicolumn{3}{|c|}{ Diversity } & \multicolumn{3}{|c|}{ Richness } & \multicolumn{3}{|c|}{ Density } \\
\hline & & MS & $F$ & $\mathrm{p}$ & MS & $F$ & $\mathrm{p}$ & MS & $F^{1}$ & $\mathrm{p}$ \\
\hline Shore & 1 & 1.4232 & 17.65 & 0.0523 & 12.1000 & 1.08 & 0.4087 & 25.7678 & 22.24 & 0.0421 \\
\hline Site(Shore) & 2 & 0.0806 & 0.89 & 0.4235 & 11.2531 & 3.37 & 0.0487 & 1.1586 & 1.72 & 0.1979 \\
\hline Boulder(Site[Shore]) & 28 & 0.0910 & 1.72 & 0.0266 & 3.3353 & 1.50 & 0.0042 & 0.6746 & 2.43 & 0.0009 \\
\hline Orientation & 3 & 0.0404 & 0.38 & 0.7751 & 2.1063 & 1.10 & 0.4686 & 0.5858 & 3.06 & 0.2838 \\
\hline Orientation $\times$ Shore & 3 & 0.1058 & 1.18 & 0.1167 & 1.9083 & 0.81 & 0.3108 & 0.0609 & 0.22 & 0.8830 \\
\hline Error & 90 & 0.0524 & & & 1.5773 & & & 0.2781 & & \\
\hline Size & 4 & 32.8641 & 917.39 & 0.0001 & 502.5484 & 487.10 & 0.0001 & 14.8003 & 151.01 & 0.0001 \\
\hline Size $\times$ Shore & 4 & 0.6974 & 2.41 & 0.1349 & 2.1937 & 2.47 & 0.1291 & 2.6637 & 4.16 & 0.0342 \\
\hline Size $\times$ Site $($ Shore $)$ & 8 & 0.2894 & 3.08 & 0.0035 & 0.8898 & 0.57 & 0.8013 & 0.5947 & 1.60 & 0.1884 \\
\hline Size $\times$ Boulder(Site[Shore]) & 112 & 0.0938 & 2.62 & 0.0001 & 1.5635 & 1.52 & 0.0023 & 0.4135 & 4.22 & 0.0001 \\
\hline Size $\times$ Orientation & 12 & 0.0444 & 0.52 & 0.8646 & 1.2964 & 0.74 & 0.6950 & 0.1840 & 1.15 & 0.4040 \\
\hline Size $\times$ Orientation $\times$ Shore & 12 & 0.0854 & 2.39 & 0.0075 & 1.7521 & 1.70 & 0.0656 & 0.1538 & 1.57 & 0.1051 \\
\hline Error & 360 & 0.0358 & & & 1.0317 & & & 0.0980 & & \\
\hline
\end{tabular}

A

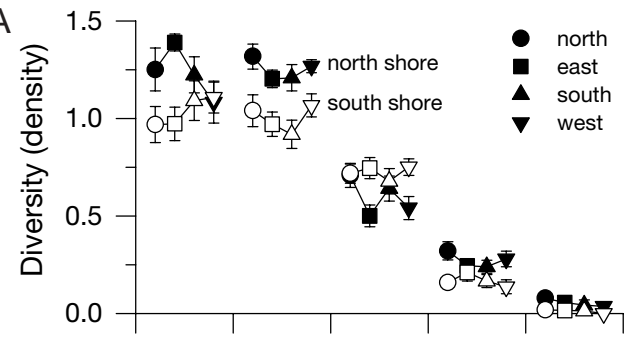

B
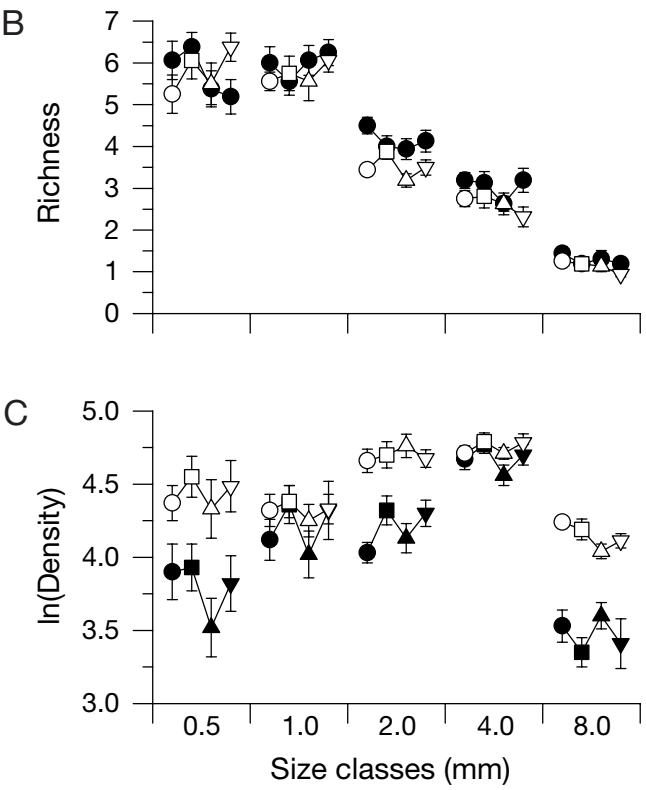

Fig. 4. Mean $( \pm \mathrm{SE})$ Shannon-Wiener diversity (A), richness (B), and density $100 \mathrm{~cm}^{-2}$ (C) of organisms within mussel communities at 4 compass ordinations on boulders from 2 shorelines examined in 1996 as a function of organism size in 1995.

North shore: black symbols; South shore: white symbols within shores. Pair-wise tests between sites within shores were usually not significant, whereas those between sites on different shores were always significant. Thus the nonparametric multivariate analyses found consistently large variation in community structure at both the $10 \mathrm{~m}$ and $50 \mathrm{~km}$ scales, lesser variation at intermediate, $10 \mathrm{~km}$, scales and an undefined but considerable amount of variation at the smallest $(<\mathrm{m})$ scale. The variation at each scale was evaluated as the mean similarity calculated for all relevant comparisons. This showed the mean similarity to decrease both with decreasing body size and increasing spatial scale (Fig. 7).

\section{Factors influencing small-scale variation in community structure}

An initial run of the complete repeated measures ANCOVA model for water flux showed the Orientation $\times$ High interaction was not significant $(p>0.25)$, satisfying the assumption of homogeneity of regressions, and was removed from the analysis. As expected, intertidal height had a significant negative effect on water flux and the magnitude of this effect varied among sampling dates (Table 5). Water flux did not however vary with respect to Orientation.

Again, initial runs of the ANCOVA models for diversity, richness and density showed that the 2 covariables (mean turbulence and intertidal height) did not vary with Orientation, satisfying the assumption of homogeneity of regressions. Subsequent runs of the models without these interaction effects found that neither of the covariables were ever significant and these too were re- 


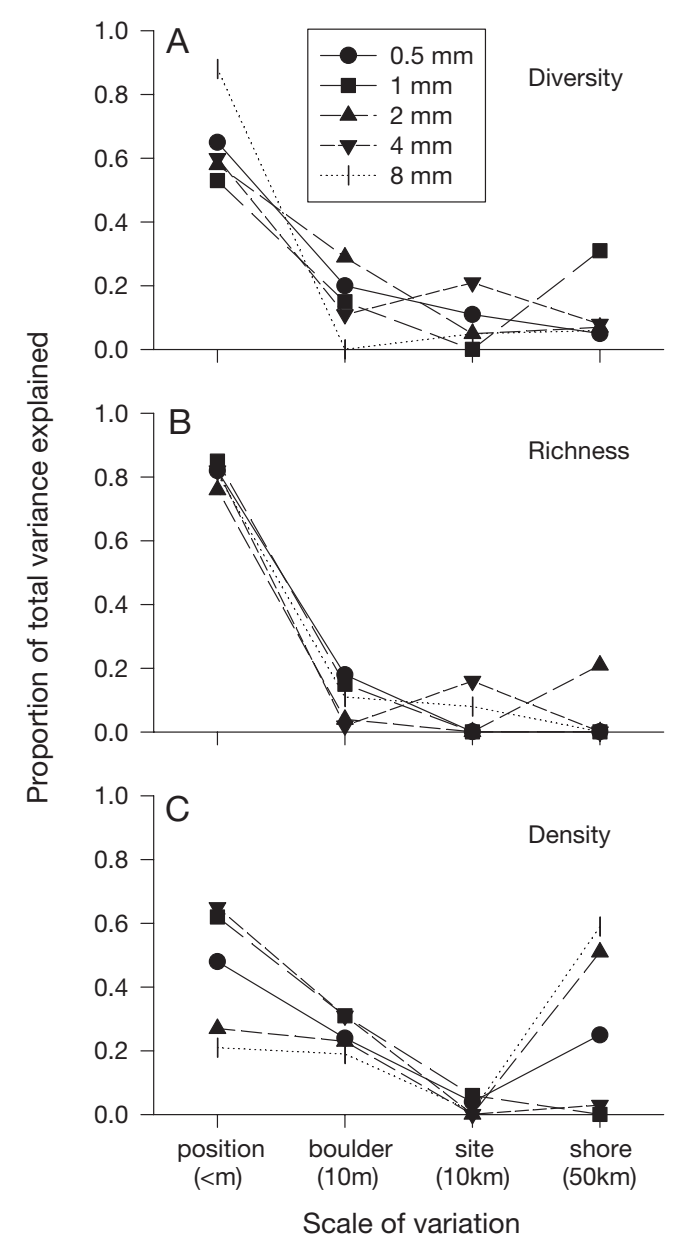

Fig. 5. Variance components (proportion of total variation explained) for Shannon-Wiener diversity (A), richness (B), and density $100 \mathrm{~cm}^{-2}$ (C) of mussel communities at 4 spatial scales in 1996 as a function of organism size. Position: observed within-boulder variation $(<1 \mathrm{~m}$ scale); Boulder: between-boulder within-site variation (10 m scale); Site: between-site within-shore variation (10 km scale); Shore: between-shore variation (50 $\mathrm{km}$ scale)

moved from all subsequent analyses. As expected, Size was always highly significant $(\mathrm{p}<0.0001)$. However, neither Orientation nor Size $\times$ Orientation was ever significant for any of the indices measured (data not shown). ANOSIM and nMDS plots also suggested no evidence of Orientation effects (data not shown).

The influence of water flux and orientation on the diversity, richness, and density of organisms on boulders as determined by stepwise regressions are given in Table 6. Diversity of the $1 \mathrm{~mm}$ size classes was positively correlated to intertidal height, and that of the $2 \mathrm{~mm}$ size class negatively to mean water flux. The opposite trend was observed for richness and density; both parameters were positively correlated to water flux for the $0.5 \mathrm{~mm}$ size class, and richness negatively to intertidal height at $4 \mathrm{~mm}$.
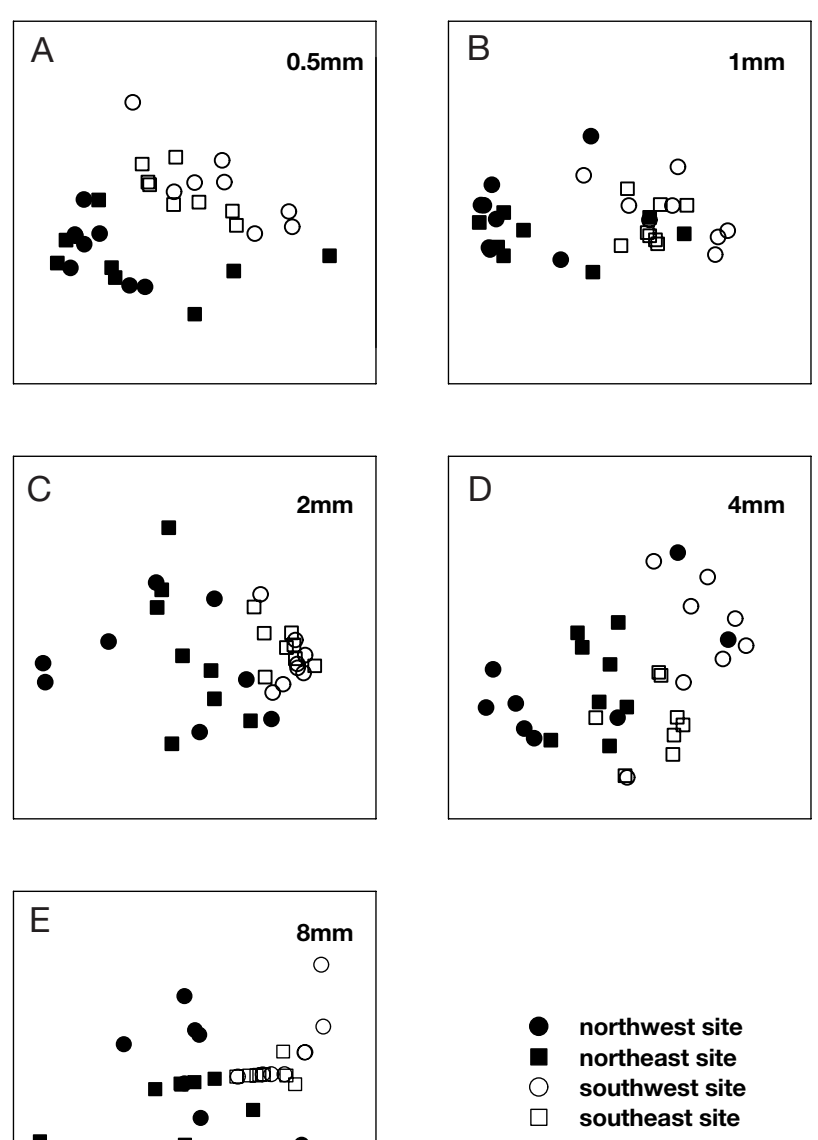

Fig. 6. nMDS plots representing the community structure of 5 size classes of organisms (A: $0.5 \mathrm{~mm}$; B: $1 \mathrm{~mm}$; C: $2 \mathrm{~mm}$; D: $4 \mathrm{~mm}$; E: $8 \mathrm{~mm}$ ) from mussel communities on boulders from each of 2 locations on both the north and south shores of the St. Lawrence estuary in 1996. For clarity, only the centroids for each boulder are shown. In all cases, stress values are $=0.16$

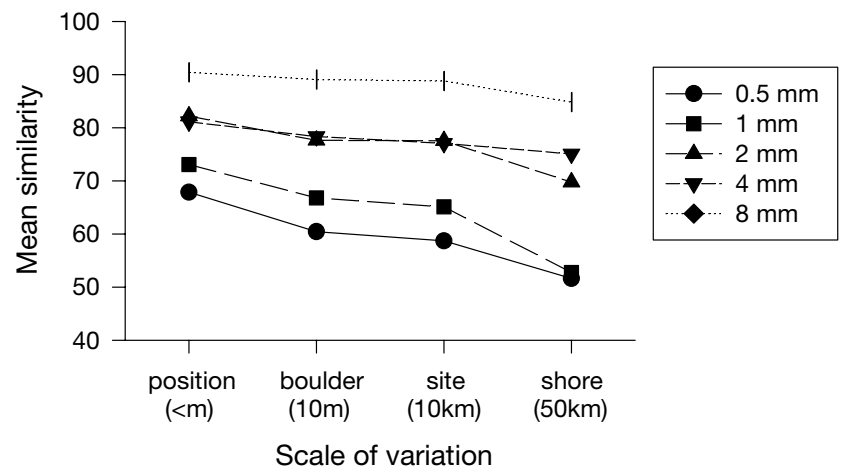

Fig. 7. Influence of organism size on the mean Bray-Curtis similarity between samples at 4 spatial scales. Axis legends are as in Fig. 5 
Table 4. Results (R statistics) from nested ANOSIMs (boulders within 4 sites) and pair-wise contrasts of community structure for the 1996 data set. Separate analyses were performed for each size class. In all cases, probabilities are based on 5000 permutations. S1 and S2 and N1 and N2 represent Sites 1 and 2 on the south shore and Sites 1 and 2 on the north shore, respectively. ns: $p>0.05 ;{ }^{*} \mathrm{p}<0.05 ;{ }^{* *} \mathrm{p}<0.01 i^{* * *} \mathrm{p}<0.001 ;{ }^{* * * *} \mathrm{p}<0.0001$

\begin{tabular}{|c|c|c|c|c|c|}
\hline \multirow[t]{2}{*}{ Source of heterogeneity } & \multicolumn{5}{|c|}{ Size class (mm) } \\
\hline & 0.5 & 1.0 & 2.0 & 4.0 & 8.0 \\
\hline Sites & $0.444^{* * * *}$ & $0.526^{* * * *}$ & $0.333^{* * * *}$ & $0.340^{* * * *}$ & $0.295^{* * *}$ \\
\hline Boulders(Sites) & $0.297^{* * * *}$ & $0.272^{* * * *}$ & $0.261^{* * * *}$ & $0.151^{* * * *}$ & $0.105^{* * * *}$ \\
\hline $\mathrm{S} 1, \mathrm{~S} 2$ & $0.165^{*}$ & $0.179^{*}$ & $0.059^{\text {ns }}$ & $0.406^{* * *}$ & $-0.028^{\mathrm{ns}}$ \\
\hline S1, N1 & $0.848^{* * *}$ & $0.882^{* * *}$ & $0.544^{* * *}$ & $0.318^{*}$ & $0.364^{* * * *}$ \\
\hline $\mathrm{S} 1, \mathrm{~N} 2$ & $0.457^{* * * *}$ & $0.617^{* * *}$ & $0.482^{* * *}$ & $0.547^{* *}$ & $0.471^{* * *}$ \\
\hline $\mathrm{S} 2, \mathrm{~N} 1$ & $0.820^{* * * *}$ & $0.927^{* * *}$ & $0.526^{* * * *}$ & $0.425^{* *}$ & $0.418^{* * * *}$ \\
\hline $\mathrm{S} 2, \mathrm{~N} 2$ & $0.400^{* * *}$ & $0.538^{* * *}$ & $0.502^{* * *}$ & $0.420^{* * * *}$ & $0.549^{* * * *}$ \\
\hline $\mathrm{N} 1, \mathrm{~N} 2$ & $0.055^{\mathrm{ns}}$ & $0.088^{\mathrm{ns}}$ & $-0.081^{\mathrm{ns}}$ & $0.103^{*}$ & $0.009^{\text {ns }}$ \\
\hline
\end{tabular}

Table 5. ANCOVA table of the influence of intertidal height (covariable) on the mean dissolution of plaster buttons (water flux) at 4 compass orientations (N, E, S and W, Orientation) on 6 separate dates (Date, repeated factor). Statistically significant values are indicated in bold

\begin{tabular}{|lrcrc|}
\hline Source of variation & df & MS & $F$ & $P$ \\
\hline Orientation & 3 & 0.0525 & 1.51 & 0.2434 \\
High & 1 & 0.3809 & 10.98 & $\mathbf{0 . 0 0 3 7}$ \\
Error & 19 & 0.0347 & & \\
Date & 5 & 0.0596 & 9.21 & $\mathbf{0 . 0 0 0 1}$ \\
Date $\times$ Orientation & 15 & 0.0123 & 1.90 & 0.0552 \\
Date $\times$ High & 5 & 0.0178 & 2.76 & $\mathbf{0 . 0 3 9 8}$ \\
Error & 95 & 0.0065 & & \\
\hline
\end{tabular}

\section{DISCUSSION}

This study showed that the structure of mussel communities in boulder fields varies at a number of spatial scales ranging from $<1 \mathrm{~m}$ to $50 \mathrm{~km}$. This was true (but variable) for each of the parametric indices of community structure calculated as well as for the nonparametric analyses. Further, this variation was also usually a function of the size of the organisms examined.

\section{Spatial scale, body size, and community structure}

The importance of the different spatial scales examined to variation in community structure (richness, diversity, density, and multivariate) differed only slightly for different sizes of organisms. Except for the density of 2 and $8 \mathrm{~mm}$ organisms, community structure was most variable at the smallest spatial scale examined (within boulders, $<1 \mathrm{~m}$ ), accounting for ca 60 , ca 80 , and $>50 \%$ of the total variation in diversity, richness and density, respectively. Comparison of the degree of scatter within and between boulders, sites, and shores in the nMDS plots and comparison of mean similarities for each scale examined in 1996 also suggest that variation at the smallest scale is probably more important than at larger scales. For all size classes, the mean similarity among samples decreased with increasing scale. However, considerable dissimilarity between samples (10 to $32 \%$ ) was detected at the smallest spatial scale examined, and this was simply increased at larger spatial scales (Fig. 7). This finding of maximal variability at the smallest spatial scale differs from studies of subtidal soft-bottom communities (Morrisey et al. 1992, Lindegarth et al. 1995, Li et al. 1996), most of which have found variation at different spatial scales to be more important. Large variation at the $<\mathrm{m}$ scale does however support the claim of Underwood \& Chapman (1996) that samples from rocky intertidal

Table 6. Summary of results from stepwise regressions of intertidal height (High), and the mean (mFlux) and the maximum (maxFlux) water flux measured around boulders versus the Diversity (calculated in terms of density), Richness, and Density $\left(100 \mathrm{~cm}^{-2}\right)$ (ln-transformed) of the communities on those boulders. Analyses were done separately for each of the 5 size classes of organism. Only significant results are shown. + and - before independent variables listed indicate positive and negative relationships between these and the dependent variables. Numbers in brackets indicate the amount of variation explained by the independent variables $\left(\mathrm{r}^{2}\right) .{ }^{*} \mathrm{p}<0.05 ;{ }^{* *} \mathrm{p}<0.01 ;{ }^{* * *} \mathrm{p}<0.005 ;{ }^{* * * *} \mathrm{p}<0.001$

\begin{tabular}{|lccc|}
\hline Size class $(\mathrm{mm})$ & Diversity & Richness & Density \\
\hline 0.5 & & + mFlux $(0.18)^{*}$ & + maxFlux $(0.37)^{* * *}$ \\
1.0 & + High $(0.19)^{*}$ & & \\
2.0 & $-\operatorname{mFlux}(0.28)^{* *}$ & & \\
4.0 & & - High $(0.28)^{* *}$ & \\
8.0 & & & \\
\hline
\end{tabular}


zones need only be separated by $<1 \mathrm{~m}$ to be considered independent. It also indicates the importance of smallscale physical heterogeneity in structuring rocky intertidal communities.

Variation in mussel community structure among boulders within sites (10 m scale) was also significant, although less so than at the smallest scale. This was true for all variables measured in at least 1 of the years studied and the magnitude of this effect was usually a function of the size class considered. Only richness and density in 1996 did not differ among sites or interact with body size. Variation at the next largest scale studied, among sites (10 km scale), was also significant but again less so than at smaller scales and was also a function of body size. Variation at the largest scale studied, between shores (50 km scale), was only tested in 1996. Although density was clearly more variable between shores than among sites, this was not the case for either diversity or richness.

Shifts in the magnitude of variation associated with different scales for different sizes of organisms as indicated by variance components calculated within the univariate parametric analyses reflect the results obtained through the calculation of similarities between samples in the multivariate nonparametric analysis. For all size classes, the mean similarity between samples decreased with increasing spatial scale. However this effect varied with organism size such that the difference in mean similarities at the different scales (between the $<1 \mathrm{~m}$ and $50 \mathrm{~km}$ scales) is $\sim 20 \%$ for the 3 smallest size classes but only by $\sim 6 \%$ for the larger ones.

As the significance of ANOSIM tests between groups depends on differences between the mean between-group and the mean within-group ranked similarities (Clarke 1993), the method should be most capable of detecting differences in community structure when the difference is maximized. For the boulder field communities examined, this suggests that detecting differences between sites within shores and between shores would be least obvious for the 2 and $8 \mathrm{~mm}$ and the 4 and $8 \mathrm{~mm}$ size classes, respectively. This was essentially the result obtained and, if general, indicates the ability to distinguish between sites may be greatest for the smallest macro-organisms.

Many studies have examined the influence of body size on the ability to detect differences between sites in order to reduce the cost of environmental impact studies (e.g., Bishop \& Hartley 1986, Ferraro et al. 1989, 1994). Such studies have usually found that increasing the mesh size reduces the power of the analysis but that the lower processing times for the larger samples allows for increased replication and lowers the overall cost of the studies (but see Schlacher \& Wooldridge 1996 for an alternative opinion). Other studies have shown that the conclusions drawn from ecological studies may be a function of the smaller size of the organisms included in the analyses (Bachelet 1990, McKindsey \& Bourget 2000, in press). However, these studies differ from this one in that the lower size limits in the other studies also include all the organisms from greater size classes. Studies examining discrete size classes in aquatic systems typically examine size spectra (Schwinghamer 1981, Cyr et al. 1997, Vidono et al. 1997). Although recent reviews (i.e., Loder et al. 1997, Blackburn \& Gaston 1998) of body size in macroecology discuss how body size frequency distributions vary among spatial scales, they do not include discussions on how spatial patterns in community structure may be influenced by the size of the organisms considered. The influence of body size on more global indices of community structure such as richness, diversity, and density remains largely unknown. Further, most studies that relate body size to species richness, density or range sizes use adult body size or the size of the largest individual observed in the study as an index of the 'body size' of all the member populations studied. This approach will result in their importance to the community structure being overemphasized and ignores the fact that differently sized organisms perceive their environment at different spatial scales and may occupy different niches (May 1978, Morse et al. 1985, Shorrocks et al. 1991). In contrast, if the smaller size classes are ignored then their importance to community structure is simply unknown.

\section{Scale-dependent variation in community structure}

Within-boulder variation was not a function of the orientation of the communities upon the boulders. This was contrary to our predictions made on the basis of our a priori ideas about wave exposure and thermal/ desiccation stress and from other studies that have reported orientation-related differences in communities on or around various objects (Farnsworth \& Ellison 1996, Cusson \& Bourget 1997, Guichard \& Bourget 1998, Glasby 1999). Orientation effects were only significant when interacting with either Shore or Size for diversity in the 1996 data set. The most obvious difference between the size classes was the elevated values for the $0.5 \mathrm{~mm}$ fraction of the communities from the east orientations on the north shore. No other analyses supported the hypothesis that the structure of mussel communities at the $<$ m scale was a function of their orientation on boulders. Neither orientation-related variation in thermal/desiccation stress nor exposure might explain this observation.

Shading has been shown to influence benthic communities (Williams 1997, Glasby 1999), including boul- 
der communities (Takada 1999), and mussel communities may be severely impacted by thermal stress (Tsuchiya 1983, Helmuth 1998). Sporadic sampling made through the summer of 1996 with a temperature probe inserted into the rock surface in the centre of the predetermined quadrats suggested that temperature regimes were most severe in the order $\mathrm{W}>\mathrm{S}>\mathrm{E}>\mathrm{N}$ around boulders (C.W.M. pers. obs.). The fact that the predicted orientation effects due to temperature were not observed in this study may be explained by a number of factors. First, the emersion time of the sampled communities may have been insufficient (all boulders sampled were in the lower middle intertidal) for thermal stress to cause noticeable effects. Alternatively, factors correlated to thermal stress such as desiccation rates may be more important in determining community structure (Brawley \& Johnson 1993). The dense structure of the mussel beds studied could have reduced stress due to desiccation, limiting any orientation effects.

Water flux was not a function of orientation around the boulders, contrary to our predictions based on other studies (i.e., Abelson et al. 1993, Breitburg et al. 1995, Cusson \& Bourget 1997, Guichard \& Bourget 1998) that found water flux to vary markedly around boulders and other roughness elements. However, these studies examined isolated objects surrounded by a more or less regular, flat, substrate, whereas those examined in this study were tightly packed. At the scale of the boulders, this close packing may shield them from direct wave impacts. It would also dramatically increase the thickness of the bottom boundary layer (Eckman 1983, Gross et al. 1992) or create stable eddies between the boulders that result in skimming flow (Green et al. 1998), further reducing the importance of the orientation of a community on a boulder to its structure. Similar effects may also occur at the scale of the mussels, which are themselves roughness elements (Fréchette et al. 1989, Green et al. 1998), further reducing the potential for water-flux-mediated effects.

However, water flux and intertidal height were correlated to community structure, although not always in the same way for all size classes. Diversity was negatively correlated to mean water flux (or positively correlated to intertidal height) for intermediate size classes of organisms. In contrast, both richness and density of the $0.5 \mathrm{~mm}$ fraction were positively correlated to water flux, and the richness of the $4 \mathrm{~mm}$ fraction was negatively correlated to intertidal height. This supports the widely held belief that water flux is important in structuring intertidal communities (Underwood \& Denley 1984, Leonard et al. 1998). Unfortunately, the method employed here does not allow us to determine whether intertidal height or water flux, which are strongly correlated $\left(\mathrm{r}^{2}=50 \%\right.$ for intertidal height and mean and maximum water flux), accounts for this correlation. We suspect that, over the intertidal range examined, water flux is more important, as the stepwise regression would usually have entered water flux into the equation had intertidal height not been included, whereas the same was not true had water flux not been included.

A few factors may account for variation at the $10 \mathrm{~m}$ scale. Although recruitment and community structure may be influenced by differences in substrata (Raimondi 1988, Lohse 1993, James \& Underwood 1994, Connolly \& Roughgarden 1998), all the boulders from which mussel communities were sampled appeared to be of the same rock type (granite) and colour, and thus variability due to this factor can probably be discounted. Alternatively, numerous studies, including the turbulence part of this study, have shown the importance of intertidal height to the structuring of intertidal communities. Variation in intertidal height may alter community structure either by altering recruitment strength (Underwood \& Denley 1984) or simply by modifying exposure regimes (Menge et al. 1994). Another possibility is that hydrodynamic regimes may differ among boulders due to differences in the local topography, but this possibility was not evaluated.

The local physico-chemical regime in the study area is rather homogenous (El-Sabh 1979), and any slight variations that do exist probably cannot account for the observed variation at the $10 \mathrm{~km}$ scale. In contrast, McKindsey \& Bourget (2000) have shown that recruitment of the major engineering species of the community, Mytilus, varies greatly along $15 \mathrm{~km}$ of the south shore studied here and have implicated this factor and variation in exposure in structuring mussel communities.

As a number of studies have noted substantial differences in the communities recruiting to collectors (buoys) moored along the 2 shores studied (Ardisson et al. 1990, Ardisson \& Bourget 1992), variation at the largest scale examined, $50 \mathrm{~km}$, was expected. Unlike the variation among sites at the $10 \mathrm{~km}$ scale, variation in community structure between shores at the $50 \mathrm{~km}$ scale may quite possibly be related to physico-chemical differences between the 2 shores. The north shore is colder and more saline than the south shore (El-Sabh 1979). Moreover, the 2 shores receive currents from different water bodies (Fradette \& Bourget 1980, Ardisson \& Bourget 1992), although both are under the influence of the freshwater outflow from north-shore rivers known as the Manicouagan and aux Outardes plume (Therriault \& Levasseur 1985). These factors could influence the number and types of species available to recruit to the 2 shores and ultimately influence community structure. Alternatively, overall differences 
in exposure between the 2 shores may influence community structure. As the major storms in the area come from the northwest, overall exposure is most likely higher along the southern shore than along the northern shore.

In conclusion, we have shown that the size of organisms examined may influence the results obtained in ecological or biomonitoring studies. Recent attempts to 'scale-up' the results from small, localized, inventory studies to greater areas (e.g., Schoch \& Dethier 1996) may well make efficient use of limited resources but considering only those taxa that are easily measured in the field (i.e., by percentage cover estimates and counts) may misrepresent the spatial distribution of the communities as a whole. Some of our results found significant spatial variation only for the smallest size classes, organisms that are typically ignored in such inventories.

Acknowledgements. We thank P. A. Paradis, M. Veret, and I. Corbet for their assistance in the field. G. Daigle (Service de Consultation Statistique, Dèpartement de mathèmatiques et de statistique, Universitè Laval) provided statistical advice, and J. Y. Anctil provided logistical support in the field. We are also grateful to P. Archambault and M. G. Chapman for comments on an earlier draft of this manuscript. This project is part of the Coastal Heterogeneity and Scaling Experiment (CHASE) and was supported by a Natural Sciences and Engineering Research Council of Canada (NSERC) grant to E.B. Funding to C.W.M. was provided through grants from the Groupe Interuniversitaire de Recherches Océanographiques du Quèbec (GIROQ), the Fondation de l'Universitè Laval, and the Fonds de soutien au doctorat from Universitè Laval.

\section{LITERATURE CITED}

Abelson A, Miloh T, Loya Y (1993) Flow patterns induced by substrata and body morphologies of benthic organisms, and their roles in determining availability of food particles. Limnol Oceanogr 38:1116-1124

Archambault P, Bourget E (1996) Scales of coastal heterogeneity and benthic intertidal species richness, diversity and abundance. Mar Ecol Prog Ser 136:111-121

Archambault P, Bourget E (1999) Influence of shoreline configuration on spatial variation of meroplanktonic larvae, recruitment and diversity of benthic subtidal communities. J Exp Mar Biol Ecol 241:309-333

Ardisson PL, Bourget E (1992) Large-scale ecological patterns: discontinuous distribution of marine benthic epifauna. Mar Ecol Prog Ser 83:15-34

Ardisson PL, Bourget E, Legendre P (1990) Multivariate approach to study species assemblages at large spatiotemporal scales: the community structure of the epibenthic fauna of the estuary and Gulf of St. Lawrence. Can J Fish Aquat Sci 47:1364-1377

Bachelet G (1990) The choice of sieving mesh size in the quantitative assessment of marine macrobenthos: a necessary compromise between aims and constraints. Mar Environ Res 30:21-35

Barry JP, Dayton PK (1991) Physical heterogeneity and the organization of marine communities. In: Kolasa J, Pickett
STA (eds) Ecological heterogeneity. Springer-Verlag, New York, p 270-320

Bell SS, Woodin SA (1984) Community unity: experimental evidence for meiofauna and macrofauna. J Mar Res 42: $605-632$

Bergeron P, Bourget E (1986) Shore topography and spatial partitioning of crevice refuges by sessile epibenthos in an ice disturbed environment. Mar Ecol Prog Ser 28:129-145

Bishop JDD, Hartley JP (1986) A comparison of the fauna retained on $0.5 \mathrm{~mm}$ and $1.0 \mathrm{~mm}$ meshes from benthic samples taken in the Beatrice Oilfield, Moray Firth, Scotland. Proc R Soc Edinb 91B:247-262

Blackburn TM, Gaston KJ (1998) Some methodological issues in macroecology. Am Nat 151:68-83

Blanchard D, Bourget E (1999) Scales of coastal heterogeneity: influence on intertidal community structure. Mar Ecol Prog Ser 179:163-173

Bourget E, DeGuise J, Daigle G (1994) Scales of substratum heterogeneity, substratum complexity and the early establishment of a marine epibenthic community. J Exp Mar Biol Ecol 181:31-51

Brawley SH, Johnson LE (1993) Predicting desiccation stress in microscopic organisms: the use of agarose beads to determine evaporation within and between microhabitats. J Phycol 29:528-535

Breitburg DL, Palmer MA, Loher T (1995) Larval distributions and the spatial patterns of settlement of an oyster reef fish: responses to flow and structure. Mar Ecol Prog Ser 125: 45-60

Bustamante RH, Branch GM, Eekhout S, Robertson B, Zoutendyk P, Schleyer M, Dye A, Hanekom N, Keats D, Jurd M, McQuaid C (1995) Gradients of intertidal primary productivity around the coast of South Africa and their relationships with consumer biomass. Oecologia 102:189-201

Caffey HM (1985) Spatial recruitment and temporal variation in settlement and recruitment of intertidal barnacles. Ecol Monogr 55:313-332

Carr MR (1996) PRIMER user manual. Plymouth Marine Laboratory, Plymouth

Chapman MG (1998) Relationships between spatial patterns of benthic assemblages in a mangrove forest using different levels of taxonomic resolution. Mar Ecol Prog Ser 162: $71-78$

Clarke KR (1993) Non-parametric analyses of changes in community structure. Aust J Ecol 18:117-143

Connolly SR, Roughgarden J (1998) A latitudinal gradient in northeast Pacific intertidal community structure: evidence for an oceanographically based synthesis of marine community theory. Am Nat 151:311-326

Cornell HV, Lawton JH (1992) Species interactions, local and regional processes, and limits to the richness of ecological communities: a theoretical perspective. J Anim Ecol 61: $1-12$

Cusson M, Bourget E (1997) Influence of topographic heterogeneity and spatial scales on the structure of the neighbouring intertidal endobenthic macrofaunal community. Mar Ecol Prog Ser 150:181-193

Cyr H, Peters RH, Downing JA (1997) Population density and community size structure: comparison of aquatic and terrestrial systems. Oikos 80:139-149

David P, Berthou P, Noel P, Jarne P (1997) Patchy recruitment patterns in marine invertebrates: a spatial test of the density-dependent hypothesis in the bivalve Spisula ovalis. Oecologia 111:331-340

Downes BJ, Keough MJ (1998) Scaling of colonization processes in streams: parallels and lessons from marine hard substrata. Aust J Ecol 23:8-26 
Eckman JE (1983) Hydrodynamic processes affecting benthic recruitment. Limnol Oceanogr 28:241-257

Eckman JE (1996) Closing the larval loop: linking larval ecology to the population dynamics of marine benthic invertebrates. J Exp Mar Biol Ecol 200:207-237

El-Sabh MI (1979) The lower St. Lawrence estuary as a physical oceanographic system. Nat Can 106:55-73

Farnsworth EJ, Ellison AM (1996) Scale-dependent spatial and temporal variability in biogeography of mangrove root epibiont communities. Ecol Monogr 66:45-66

Ferraro SP, Cole FA, DeBen WA, Swartz RC (1989) Power-cost efficiency of eight macrobenthic sampling schemes in Puget Sound, Washington, USA. Can J Fish Aquat Sci 46: $2157-2165$

Ferraro SP, Swartz RC, Cole FA, Deben WA (1994) Optimum macrobenthic sampling protocol for detecting pollution impacts in the Southern California Bight. Environ Monit Assess 29:127-153

Fradette P, Bourget E (1980) Ecology of benthic epifauna of the estuary and Gulf of St. Lawrence: factors influencing their distribution and abundance on buoys. Can J Fish Aquat Sci 37:979-999

Fréchette M, Butman CA, Geyer WR (1989) The importance of boundary-layer flows in supplying phytoplankton to the benthic suspension feeder Mytilus edulis L. Limnol Oceanogr 34:19-36

Glasby TM (1999) Effects of shading on subtidal epibiotic assemblages. J Exp Mar Biol Ecol 234:275-290

Green MO, Hewitt JE, Thrush SF (1998) Seabed drag coefficient over natural beds of horse mussels (Atrina zelandica). J Mar Res 56:613-637

Gross TF, Werner FE, Eckman JE (1992) Numerical modeling of larval settlement in turbulent bottom boundary layers. J Mar Res 50:611-642

Guichard F, Bourget E (1998) Topographic heterogeneity, hydrodynamics, and benthic community structure: a scale-dependent cascade. Mar Ecol Prog Ser 171:59-70

Helmuth BST (1998) Intertidal mussel microclimates: predicting the body temperature of a sessile invertebrate. Ecol Monogr 68:51-74

Hurlbert SH (1997) Functional importance vs keystoneness: reformulating some questions in theoretical biocenology. Aust J Ecol 22:369-382

James RJ, Underwood AJ (1994) Influence of colour of substratum on recruitment of spirorbid tubeworms to different types of intertidal boulders. J Exp Mar Biol Ecol 181: 105-115

James RJ, Lincoln Smith MP, Fairweather PG (1995) Sieve mesh-size and taxonomic resolution needed to describe natural spatial variation of marine macrofauna. Mar Ecol Prog Ser 118:187-198

Jumars PA, Nowell ARM (1984) Fluid and sediment dynamic effects on marine benthic community structure. Am Zool 24:45-55

Kolasa J, Pickett STA (eds) (1991) Ecological heterogeneity. Springer-Verlag, New York

Legendre P, Thrush SF, Cummings VJ, Dayton PK, Grant J, Hewitt JE, Hines AH, McArdle BH, Pridmore RD, Schneider DC, Turner SJ, Whitlach RB, Wilkinson MR (1997) Spatial structure of bivalves in a sandflat: scale and generating processes. J Exp Mar Biol Ecol 216:99-128

Leonard GH, Levine JM, Schmidt PR, Bertness MD (1998) Flow-driven variation in intertidal community structure in a Maine estuary. Ecology 79:1395-1411

Li J, Vincx M, Herman PMJ, Heip C (1996) Monitoring meiobenthos using $\mathrm{cm}-, \mathrm{m}$ - and $\mathrm{km}$-scales in the southern bight of the North Sea. Mar Environ Res 43:265-278
Lindegarth M, André C, Jonsson PR (1995) Analysis of the spatial variability in abundance and age structure of two infaunal bivalves, Cerastoderma edule and C. lamarcki, using hierarchical sampling programs. Mar Ecol Prog Ser 116:85-97

Loder N, Blackburn TM, Gaston KJ (1997) The slippery slope: towards an understanding of body size frequency distribution. Oikos 78:195-201

Lohse DP (1993) The effects of substratum type on the population dynamics of three common intertidal animals. J Exp Mar Biol Ecol 173:133-154

May RM (1978) The dynamics and diversity of insect faunas. In: Mound LA, Waloff N (eds) Diversity of insect faunas. Blackwell Scientific Publications, London, p 188-204

McKindsey CW, Bourget E (2000) Explaining mesoscale variation in intertidal mussel community structure. Mar Ecol Prog Ser 205:155-170

McKindsey CW, Bourget E (in press) Diversity of a northern rocky intertidal community: the influence of body size and succession. Ecology

Menconi ML, Benedetti-Cecchi L, Cinelli F (1999) Spatial and temporal variability in the distribution of algae and invertebrates on rocky shores in the northwest Mediterranean. J Exp Mar Biol Ecol 233:1-23

Menge BA, Berlow EL, Blanchette CA, Navarrete SA, Yamada SB (1994) The keystone species concept: variation in interaction strength in a rocky intertidal habitat. Ecol Monogr 64:249-286

Morrisey DJ, Howitt L, Underwood AJ, Stark JS (1992) Spatial variation in soft-sediment benthos. Mar Ecol Prog Ser 81: 197-204

Morse DR, Lawton JH, Dodson MM, Williamson MH (1985) Fractal dimension of vegetation and the distribution of arthropod body lengths. Nature 314:731-733

Muschenheim DK (1987) The dynamics of near-bed seston flux and suspension-feeding benthos. J Mar Res 45: $473-496$

Muus BJ (1968) A field method for measuring 'exposure' by means of plaster balls. Sarsia 34:61-68

Ólafsson EB, Peterson CH, Ambrose Jr WG (1994) Does recruitment limitation structure populations and communities of macro-invertebrates in marine soft sediments: the relative significance of pre- and post settlement processes. Oceanogr Mar Biol Annu Rev 32:65-109

Palmer MA (1986) Hydrodynamics and structure: interactive effects on meiofauna dispersal. J Exp Mar Biol Ecol 104: $53-68$

Patterson MR (1984) Patterns of whole colony prey capture in the octocoral, Alcyonium siderium. Biol Bull 167: 613-629

Peters RH (1983) The ecological implications of body size. Cambridge University Press, New York

Raimondi PT (1988) Rock type affects settlement, recruitment, and zonation of Chthamalus anisopoma Pilsbury. J Exp Mar Biol Ecol 123:253-267

Rice WR (1989) Analyzing tables of statistical tests. Evolution 43:223-225

Ricklefs RE, Schluter D (1993) Species diversity in ecological communities: historical and geographical perspectives. The University of Chicago Press, Chicago

SAS Institute (1996) The SAS system for Windows. SAS Institute Inc, Cary, NC

Schlacher TA, Wooldridge TH (1996) How sieve mesh size affects sample estimates of estuarine benthic macrofauna. J Exp Mar Biol 201:159-171

Schoch GC, Dethier MN (1996) Scaling up: the statistical link- 
age between organismal abundance and geomorphology on rocky intertidal shores. J Exp Mar Biol 201:37-72

Shorrocks B, Marsters J, Ward I, Evennett PJ (1991) The fractal dimension of lichens and the distribution of arthropod body lengths. Function Ecol 5:457-460

Schwinghamer P (1981) Characteristic size distributions of integral benthic communities. Can J Fish Aquat Sci 38: 1255-1263

Tabachnick BD, Fidell LS (1989) Using multivariate statistics. Harper \& Row, New York

Takada Y (1999) Influence of shade and number of boulder layers on mobile organisms on a warm temperate boulder shore. Mar Ecol Prog Ser 189:171-179

Therriault JC, Levasseur M (1985) Control of phytoplankton production in the lower St. Lawrence estuary: light and freshwater runoff. Nat Can 112:77-96

Thompson RC, Wilson BJ, Tobin ML, Hill AS, Hawkins SJ (1996) Biologically generated habitat provision and diversity of rocky shore organisms at a hierarchy of spatial scales. J Exp Mar Biol 202:73-84

Tsuchiya M (1983) Mass mortality of the mussel Mytilus

Editorial responsibility: Otto Kinne (Editor),

Oldendorf/Luhe, Germany edulis L. caused by high temperature on rocky shores. J Exp Mar Biol Ecol 66:101-111

Underwood AJ (1997) Experiments in ecology: their logical design and interpretation using analysis of variance. Cambridge University Press, Cambridge

Underwood AJ, Chapman MG (1996) Scales of spatial patterns of distribution of intertidal invertebrates. Oecologia 107:212-224

Underwood AJ, Denley EJ (1984) Paradigms, explanations, and generalizations in models for the structure of intertidal communities on rocky shores. In: Simberloff D, Strong DR (eds) Ecological communities: conceptual issues and the evidence. Princeton University Press, Princeton, p 151-180

Vidono B, Prairie YT, Blanco JM, Duarte CM (1997) Some aspects of the analysis of size spectra in aquatic ecology. Limnol Oceanogr 42:184-192

Williams GA (1997) The relationship between shade and molluscan grazing in structuring communities on a moderately-exposed tropical rocky shore. J Exp Mar Biol Ecol 178:79-95

Submitted: December 15, 1998; Accepted: February 20, 2001 Proofs received from author(s): June 12, 2001 